\title{
From bowel inflammation to the bone and joints: musculoskeletal examination in inflammatory bowel disease (IBD)
}

Samane Tavassoli', Iman Shahabinasab², Alireza Norouzi² ${ }^{1}$ Taghi Amiriani ${ }^{2}$, Nafiseh Abdolahi ${ }^{1}$, Somayeh Livani ${ }^{3}$, Seyed Farzam Mirkamali², Honey Sadat Mirkarimi ${ }^{2}$, Fazel Isapanah Amlashi ${ }^{2}$ and Sima Besharat ${ }^{2 *}$

\begin{abstract}
Background: One of the most important complications in inflammatory Bowel Disease (IBD) are musculoskeletal manifestations that are reported in more than $50 \%$ of patients.

Objectives: In this study, we aimed to evaluate the musculoskeletal and radiologic manifestations in our IBD patients.

Methods: In this cross-sectional study on 96 mild-to-moderate IBD patients (76 UC, 18 CD and 2 undifferentiated IBD) with mean (SD) age of 39.28 (11.42) years, 44 (45.8\%) were males and 52 were (54.2\%) females. Patients were examined by an expert rheumatologist and their musculoskeletal symptoms were assessed. The musculoskeletal system was evaluated by Modified Schober test, Thoracic expansion (TE), Occiput to wall distance (OWD), and Patrick's or FABER test. Peripheral joints were also examined in all four extremities. Then patients were referred for pelvic and lumbosacral $x$-ray. Sacroiliitis grading was performed using the New York criteria.
\end{abstract}

Results: Inflammatory low back pain was reported in 5 (5.2\%), enthesopathy in $6(6.5 \%)$ and dactylitis in 1 (1.1\%). Positive Schober test was recorded in 5 (5.2\%) and Patrick test in 3 (3.1\%). Forty-nine (51\%) cases had normal imaging with no sacroiliitis, endplate sclerosis was seen in 33 cases (34.4\%), grade 3 and grade 4 were seen in 10 cases (10.4\%).

Conclusions: In the present study, 34.4\% of the IBD patients had mild radiologic changes as endplate sclerosis and 95\% had a normal physical examination.

Keywords: Inflammatory bowel disease, Sacroiliitis, Enthesitis

\section{Background}

Inflammatory bowel disease (IBD) is a chronic inflammatory disease composed of Crohn's disease (CD) and ulcerative colitis. The etiology of IBD remains unknown but it is believed that the interaction of genetics, environment and immune system play a major role [1]. There is

\footnotetext{
*Correspondence: s_besharat_gp@yahoo.com

${ }^{2}$ Golestan Research Center of Gastroenterology and Hepatology, GolestanUniversity of Medical Sciences, 3rd floor, Heart Complex, Sayyad-e-Shirazi Hospital, Sayyad-e-Shirazi Boulevard, Gorgan city, Golestan province, Iran

Full list of author information is available at the end of the article
}

no curative therapy for IBD and the goal of treatment is to prevent complications and reducing the progression of inflammation [2].

Extra intestinal manifestations (EIM) are common in IBD patients. More than half of the patients experience at least one extra intestinal symptom during their lifetime [3]. The incidence of EIM varies from 6 to $47 \%$. Extraintestinal manifestations of IBD can affect many systems in the body such as musculoskeletal, ocular, dermatologic, hepatobiliary and etc. But one of the most common complications of IBD is musculoskeletal (MSK) manifestations. Approximately more than 50\% original author(s) and the source, provide a link to the Creative Commons licence, and indicate if changes were made. The images or other third party material in this article are included in the article's Creative Commons licence, unless indicated otherwise in a credit line to the material. If material is not included in the article's Creative Commons licence and your intended use is not permitted by statutory regulation or exceeds the permitted use, you will need to obtain permission directly from the copyright holder. To view a copy of this licence, visit http://creativecommons.org/licenses/by/4.0/. The Creative Commons Public Domain Dedication waiver (http://creativeco mmons.org/publicdomain/zero/1.0/) applies to the data made available in this article, unless otherwise stated in a credit line to the data. 
of IBD patients, develop MSK complications including axial and peripheral arthritis [4-6].

Axial arthritis consists of sacroiliitis and ankylosing spondylitis (AS), which are not associated with intestinal disease activity. Ankylosing Spondylitis has been reported in 5 to $10 \%$ of IBD patients. These patients complain about back pain and dryness at night, during the morning, and after immobility. Pure sacroiliitis is a common finding (up to $20 \%$ of patients) but it is asymptomatic in many patients $[7,8]$.

Spondyloarthritis (SpA) is divided into two types: peripheral and axial. Peripheral involvement can be divided into two subtypes: subtype 1 (non-destructive) asymmetrically affects the large joints including the knee, hip, wrist, elbow, and ankle that associated with bowel disease activity. Mostly it lasts only a few weeks with no clear radiologic manifestations. But subtype 2 (destructive) involves the small joints symmetrically and has no clear association with IBD [9-11].

Common available medications for IBD are AntiTNF alpha drugs, amino salicylates, corticosteroids and immunomodulators. Corticosteroids have systemic effects and maybe there will be limits in some patients in order to use them. Recent studies have shown that Anti-TNF agents are effective to induce remission in both adults and children. Infliximab and Adalimumab are the only Anti-TNF agents that approved by Food and drug administration (FDA). Prescribing these drugs has reduced the use of corticosteroids [12].

The treatment of IBD and rheumatologic musculoskeletal complications are similar to the treatment of IBD itself (using 5-ASA combinations like Sulfasalazine), but the question is, does IBD treatment affects MSK? [13, 14].

In this study, we aimed to evaluate the musculoskeletal and radiologic manifestations in IBD patients.

\section{Method}

\section{Study population and design}

In this cross-sectional study, 100 registered IBD patients were recruited: 4 were excluded during the study because of pregnancy, among 96 remained patients, 76 were UC, 18 Crohn's disease and 2 undifferentiated IBD. Patients were invited to the Golestan Research Center of Gastroenterology and Hepatology (GRCGH) by telephone call.

\section{Inclusion criteria}

All IBD patients registered in the IBD bank have been reached out through the telephone, and recruited into the study if agreed to terms of the study.

\section{Exclusion criteria}

Hospital admission at the time of study and during the last month, history of fracture or trauma after the diagnosis of IBD, pregnancy and not willing to have an $\mathrm{x}$-ray were among the exclusion criteria.

Patients were examined by an expert rheumatologist and their musculoskeletal symptoms were assessed throughout the following tests to evaluate the musculoskeletal symptoms: modified Schober test, Thoracic expansion (TE), Occiput to wall distance (OWD) and Patrick's test or FABER test [15]. Peripheral joints of all four extremities were also examined.

\section{Radiological evaluation}

After finishing the physical examination and completing the questionnaire throughout a face-to-face interview, patients were referred to a well-equipped imaging center to perform a pelvic and lumbosacral $x$-ray. The radiologist blinded to the rheumatologic exam findings.

Sacroiliitis grading was performed using the New York criteria [16]:

\section{Grade 0: Normal imaging}

Grade 1: some blurring of the joint margins (Suspicious)

Grade 2: Minimal sclerosis with some erosion

Grade 3: definite sclerosis on both sides of joint / severe erosions with widening of joint space with or without ankyloses

Grade 4: complete ankyloses

Radiologic reports were all seen and graded by one expert radiologist. Those patients with problems in their X-ray were referred for further managements. Rheumatologic and radiologic findings analyzed by another rheumatologist.

\section{Results}

In this study on 96 IBD patients (76 UC, $18 \mathrm{CD}$ and 2 undifferentiated IBD) with mean (SD) of 39.28 (11.42) years, there were $44(45.8 \%)$ males and 52 (54.2\%) females. Table 1 shows the demographic variables of the study population.

History taking and physical examination showed inflammatory low back pain in $5(5.2 \%)$, enthesopathy in $6(6.5 \%)$ and dactilitis in $1(1.1 \%)$. Rheumatologic examinations of the studied population showed positive Schober test in $5(5.2 \%)$ and positive Patrick test in 3 (3.1\%) Table 2.

Lumbosacral and pelvic X-ray reports are shown in Table 3. Forty-nine (51\%) cases had normal imaging with no sacroilleitis, endplate sclerosis was seen in 33 cases 
Table 1 Demographic and anthropometric data of the studied population of IBD

\begin{tabular}{ll}
\hline Age, Mean (SD), years & $\mathbf{3 9 . 2 8} \mathbf{( 1 1 . 4 2 )}$ \\
\hline Sex, N (\%) & \\
Male & $44(45.8)$ \\
Female & $52(54.2)$ \\
Type of IBD, N (\%) & \\
UC & $76(79.2)$ \\
CD & $18(18.8)$ \\
Undifferentiated & $2(2.1)$ \\
Duration of the bowel disease, Median (SE) & $5(0.65)$ \\
Body Mass Index (BMI), Mean (SD), kg/m2 & $26.26(4.36)$ \\
BMI group, N (\%) & \\
Underweight (<18.5) & $1(1)$ \\
Normal (18.5-24.9) & $52(54.2)$ \\
Overweight (25-29) & $27(28.1)$ \\
Obese ( $\geq 30)$ & $16(16.7)$ \\
Waist circumference, Mean (SD), cm & $89.35(10.40)$ \\
Abdominal circumference, Mean (SD), cm & $97.4(10.97)$ \\
Medication, N (\%) & \\
Sulfunamides (Asacol, Mesalazine, Sulfasalazine) & $78(81.2)$ \\
Anti-TNF (Remicade, Cinnora) & $18(18.8)$ \\
Azathioprine & $39(40.6)$ \\
Prednisolone & $37(38.5)$ \\
\hline
\end{tabular}

Table 2 Results of the rheumatologic examinations in IBD patients

\begin{tabular}{ll}
\hline Occiput to Wall Distance, Mean (SD), cm & $\mathbf{4 . 3 1}$ (1.66) \\
\hline Schober test, N (\%) & \\
$\quad$ Positive & $5(5.2)$ \\
$\quad$ Negative & $91(94.8)$ \\
Schober index, Mean (SD), cm & $6.94(1.30)$ \\
Patrick test, N (\%) & \\
$\quad$ Positive & $3(3.1)$ \\
$\quad$ Negative & $93(96.9)$ \\
Inflammatory Low Back Pain, N (\%) & \\
$\quad$ Positive & $5(5.2)$ \\
$\quad$ Negative & $91(94.8)$ \\
Peripheral arthropathy, N (\%) & \\
$\quad$ Upper extremities & \\
$\quad$ Left & $2(2.1)$ \\
$\quad$ Right & $2(2.1)$ \\
Lower extremities & \\
$\quad$ Left & $2(2.1)$ \\
$\quad$ Right & $2(2.1)$ \\
Dactilitis, N (\%) & $1(1.1)$ \\
Enthesopathy, N (\%) & $6(6.5)$ \\
\hline
\end{tabular}

Table 3 Radiologic manifestation in IBD patients

\begin{tabular}{ll}
\hline End plate sclerosis in Lumbosacral joint, $\mathbf{N}(\%)$ & $\mathbf{3 3}(\mathbf{3 4 . 4 )}$ \\
\hline Sacroilleitis grades, N (\%) & \\
$\quad$ Grade 0 (Normal imaging) & $49(51)$ \\
Grade 1 (Suspicious) & $14(14.6)$ \\
Grade 2 (Minimal sclerosis with some erosion) & $23(24)$ \\
Grade 3 (definite sclerosis on both sides with or without & $8(8.3)$ \\
ankyloses) & $2(2.1)$ \\
Grade 4 (complete ankyloses) & \\
\hline
\end{tabular}

(34.4\%), and definite sclerosis on both sides with or without ankyloses (grade 3) and complete ankyloses (grade 4) were seen in 10 cases (10.4\%).

Twenty one patients were taking Anti-TNF drug (22\%), 42 (44\%) Azathioprine and 40 (42\%) were taking Prednisolone. Because of small number of patients who were taking Anti-TNF medication, it is not possible to find significant relationship between treatment and radiologic manifestations. Only $12 \%$ of patients who were treating by Anti-TNF medications had grade 2 or higher sacroiliitis. (Vs. $24.6 \%$ in patients who were not taking Anti-TNF).

\section{Discussion}

In this study regards to the evaluation of the musculoskeletal manifestations in patients with IBD, severity of the disease was measured on the basis of New York criteria and musculoskeletal symptoms were assessed on the basis of radiological observations and physical examination of patients. Numerous reports from different countries showed various range of rheumatologic symptoms (2 to $46 \%$ ) [17].

In our study, patients had few obvious musculoskeletal symptoms as inflammatory low back pain in 5.2\%, enthesopathy in $6.5 \%$ and dactylitis in $1.1 \%$. This may be due to the treatment with immunosuppressive and immunomodulatory medications [18]. As mentioned before, approximately $50 \%$ of IBD patients experience at least one rheumatologic manifestation in their lifetime, but the mean duration of the disease was 5 years in the present study. During the years after the first diagnosis, the probability of rheumatologic manifestations would be more prominent. So, some may develop rheumatologic complications in the next coming years.

The small number of patients compared to the studies mentioned can be a reason for minor differences in radiological results as well as physical examinations. Interestingly, the study by Giani et al. performed on 34 IBD patients, no one had symptoms in physical examination, but sacroiliitis reported in 15\% of them on Magnetic Resonance Enterography (MRE) [19]. 
In our study, $34.4 \%$ of patients had radiologic changes as end plate sclerosis, but positive physical exams were seen in less than $5 \%$ of them. The bowel activity index was more than 6 just in 4 cases indicating that most of our patients were in the remission phase.

The modality used for evaluation of sacroiliitis can affect the result. As in a study in Canada the prevalence of sacroiliitis was three times higher in IBD patients than in the control group evaluated by CT scan [20].

In this regards, a review study in Italy stated that pelvic radiography often identifies $\mathrm{SpA}$ in its late stages and MRI is the goal standard diagnostic imaging for assess SpA [21].

Another study in France showed a 9.8\% prevalence of sacroiliitis in their IBD patients with CT scan and 15.7\% with MRE [22].

But another study in Canada found sacroiliitis in 16\% of their IBD patients through radiological examinations [23], similar to our results.

A study in Italy has also reported that some patients with asymptomatic IBD have radiologic evidence of spondyloarthritis [6]. Asymptomatic patients are often less treated and less likely to adhere to treatment than symptomatic patients. On the other hand, asymptomatic patients have fewer referrals to a physician, and their rheumatologic symptoms are expected to be diagnosed later.

As shown in another study from Korea, ankylosing spondylitis and rheumatoid arthritis are more common in IBD patients than other rheumatologic diseases [24].

In the present study, endplate sclerosis was seen in $34.4 \%$ and higher grade of sacroilliitis (grade 3 and 4 ) was reported in $10.4 \%$ of IBD cases, although they were clinically asymptomatic, probably due to the prescribed treatment.

It has been suggested that genetic factors, and even the microbiome composition of IBD patients, could make a difference in musculoskeletal manifestations [25]. Therefore, the potential role of genetics in the presence of extra intestinal symptoms in patients should be considered. Further studies are needed to investigate these factors.

\section{Conclusion}

In our study, one-third of patients (34.4\%) had mild radiologic changes as endplate sclerosis and $94-95 \%$ of patients had a normal physical examination. Therefore, it can be concluded that even patients who have radiologic manifestations may have normal physical examinations. Medication use and short duration of illness are probably important reasons for the normal physical examination of our patients.

\section{Limitations}

One of the most important limitation of this study was the small number of patients. And the other one was a Poor patient cooperation due to difficulty in referral or dissatisfaction. So, we were unable to follow them to assess whether symptoms changes or not.

\section{Acknowledgments \\ This paper has been extracted partly from the doctorate thesis dedicated to achieve the MD degree in Golestan University of Medical Sciences. Authors tend to thank all colleagues in Golestan Research Center of Gastroenterology and hepatology (GRCGH).}

\section{Authors' contributions}

S.T, N.A and S.L. contributed in the concept and design of the study, the acquisition and interpretation of data, provided final approval of the version to publish. S.F.M, H.S.M. F.I.A. and I.SH. contributed in data collection, drafted manuscript preparation, and provided final approval of the version to publish. A.N. and T.A. contributed in the acquisition and interpretation of data, drafted manuscript preparation and provided final approval of the version to publish. S.B. contributed in analysis and interpretation of data, drafted critical revision of the article and provided final approval of the version to publish.

\section{Funding}

Authors tend to thank deputy of research for the financial support.

\section{Availability of data and materials}

The datasets used and analyzed during the current study but not publicly available due to limitations of ethical approval involving the patient data and anonymity but are available from the corresponding author on reasonable request.

\section{Declarations}

\section{Ethics approval and consent to participate}

This study was approved in the local ethical committee of Golestan University of Medical Sciences (IR.GOUMS.REC.1398.155). The aim of study was explained for all and those who tended to enter to study signed an informed consent. All methods were carried out in accordance with relevant guidelines and regulations.

\section{Consent for publication}

Not applicable.

\section{Competing interests}

Authors declare no conflict of interests.

\section{Author details}

${ }^{1}$ Golestan Rheumatology Research Center, Golestan University of Medical Sciences, Gorgan, Iran. ${ }^{2}$ Golestan Research Center of Gastroenterology and Hepatology, GolestanUniversity of Medical Sciences, 3rd floor, Heart Complex, Sayyad-e-Shirazi Hospital, Sayyad-e-Shirazi Boulevard, Gorgan city, Golestan province, Iran. ${ }^{3}$ Clinical Research Development Unit (CRDU), Sayad Shirazi Hospital, Golestan University of Medical Sciences, Gorgan, Iran.

Received: 7 March 2021 Accepted: 24 November 2021

Published online: 04 December 2021

\section{References}

1. Baumgart DC, Carding SR. Inflammatory bowel disease: cause and immunobiology. Lancet. 2007;369(9573):1627-40.

2. Triantafillidis JK, Merikas E, Georgopoulos F. Current and emerging drugs for the treatment of inflammatory bowel disease. Drug Des Dev Ther. 2011;5:185.

3. Harbord M, Annese V, Vavricka SR, Allez M, Barreiro-de Acosta M, Boberg KM, et al. The first European evidence-based consensus on 
extra-intestinal manifestations in inflammatory bowel disease. J Crohns Colitis. 2016;10(3):239-54.

4. Cardoneanu A, Prelipcean CC, Danciu M, Mihai C, Dranga M, Gavrilescu O, et al. Looking beyond gut inflammation in inflammatory bowel. Romanian J Morphol Embryol. 2018;59(4):1097-105.

5. Sarbu MI, Sarbu N. Musculoskeletal clinical and imaging manifestations in inflammatory bowel diseases. Open Med. 2019;14(1):75-84.

6. Zippi M, Corrado C, Pica R, Avallone EV, Cassieri C, De Nitto D, et al. Extraintestinal manifestations in a large series of Italian inflammatory bowel disease patients. World J Gastroenterol. 2014;20(46):17463.

7. Zochling J, Braun J, van der Heijde D. Assessments in ankylosing spondylitis. Best Pract Res Clin Rheumatol. 2006;20(3):521-37.

8. Assassi S, Weisman MH, Lee M, Savage L, Diekman L, Graham TA, et al. New population-based reference values for spinal mobility measures based on the 2009-2010 National Health and nutrition examination survey. Arthritis Rheumatol. 2014;66(9):2628-37.

9. Arvikar SL, Fisher MC. Inflammatory bowel disease associated arthropathy. Curr Rev Musculoskelet Med. 2011;4(3):123-31.

10. Voulgari PV. Rheumatological manifestations in inflammatory bowel disease. Ann Gastroenterol. 2011;24(3):173.

11. Olpin JD, Sjoberg BP, Stilwill SE, Jensen LE, Rezvani M, Shaaban AM. Beyond the bowel: extraintestinal manifestations of inflammatory bowel disease. Radiographics. 2017;37(4):1135-60.

12. Aardoom MA, Veereman $G$, de Ridder $L$. A review on the use of anti-TNF in children and adolescents with inflammatory bowel disease. Int J Mol Sci. 2019;20(10):2529.

13. Palazzi C, D'Angelo S, Gilio M, Leccese P, Padula A, Olivieri I. Pharmacological therapy of spondyloarthritis. Expert Opin Pharmacother. 2015;16(10):1495-504

14. Pouillon L, Bossuyt P, Peyrin-Biroulet L. Considerations, challenges and future of anti-TNF therapy in treating inflammatory bowel disease. Expert Opin Biol Ther. 2016;16(10):1277-90.

15. Antonelli-Incalzi R, Pedone C, Cesari M, Di lorio A, Bandinelli S, Ferrucci L. Relationship between the occiput-wall distance and physical performance in the elderly: a cross sectional study. Aging Clin Exp Res. 2007;19(3):207-12.

16. Linden SVD, Valkenburg HA, Cats A. Evaluation of diagnostic criteria for ankylosing spondylitis. Arthritis Rheum. 1984;27(4):361-8.

17. Bennebroek Evertsz'F, Nieuwkerk PT, Stokkers PC, Ponsioen CY, Bockting $\mathrm{CL}$, Sanderman R, et al. The patient simple clinical colitis activity index (P-SCCAI) can detect ulcerative colitis (UC) disease activity in remission: a comparison of the P-SCCAI with clinician-based SCCAI and biological markers. J Crohns Colitis. 2013;7(11):890-900.

18. Callhoff J, Sieper J, Weiß A, Zink A, Listing J. Efficacy of TNFa blockers in patients with ankylosing spondylitis and non-radiographic axial spondyloarthritis: a meta-analysis. Ann Rheum Dis. 2015;74(6):1241-8.

19. Giani T, Bernardini A, Basile M, Di Maurizo M, Perrone A, Renzo S, et al. Usefulness of magnetic resonance enterography in detecting signs of sacroiliitis in young patients with inflammatory bowel disease. Pediatr Rheumatol. 2020;18:1-6.

20. Chan J, Sari I, Salonen D, Silverberg MS, Haroon N, Inman RD. Prevalence of sacroiliitis in inflammatory bowel disease using a standardized computed tomography scoring system. Arthritis Care Res. 2018;70(5):807-10.

21. Becciolini A, Di Donato E, Lucchini G, Santilli D, Mozzani F, Riva M, et al. Imaging in the assessment of musculoskeletal manifestations associated with inflammatory bowel disease. Gastroenterol Insights. 2021;12(1):100-10.

22. Fauny M, Cohen N, Morizot C, Leclerc-Jacob S, Wendling D, Lux G, et al. Low back pain and sacroiliitis on cross-sectional abdominal imaging for axial spondyloarthritis diagnosis in inflammatory bowel diseases. Inflamm Intest Dis. 2020;5(3):124-31.

23. Kelly OB, Li N, Smith M, Chan J, Inman RD, Silverberg MS. The prevalence and clinical associations of subclinical sacroiliitis in inflammatory bowel disease. Inflamm Bowel Dis. 2019;25(6):1066-71.

24. Bae JM, Choo JY, Kim K-J, Park K-S. Association of inflammatory bowel disease with ankylosing spondylitis and rheumatoid arthritis: a nationwide population-based study. Mod Rheumatol. 2017;27(3):435-40.

25. Bandinelli F, Manetti M, Ibba-Manneschi L. Occult spondyloarthritis in inflammatory bowel disease. Clin Rheumatol. 2016;35(2):281-9.

\section{Publisher's Note}

Springer Nature remains neutral with regard to jurisdictional claims in published maps and institutional affiliations.
Ready to submit your research? Choose BMC and benefit from:

- fast, convenient online submission

- thorough peer review by experienced researchers in your field

- rapid publication on acceptance

- support for research data, including large and complex data types

- gold Open Access which fosters wider collaboration and increased citations

- maximum visibility for your research: over $100 \mathrm{M}$ website views per year

At BMC, research is always in progress.

Learn more biomedcentral.com/submissions 